\title{
Simulation Method of Hydraulic Confined Piston Engine
}

\author{
JIAO Yuqin ${ }^{1, a}$, ZHANG Hongxin ${ }^{1, b^{*}}$ and XU Wei $i^{1, c}$ \\ ${ }^{1}$ Electromechanic Engineering College of Qingdao University, China \\ ajiaoyuqin_qdu@126.com, b ${ }^{\mathrm{b}} \mathrm{zhx@qdu.edu.cn,{ } ^ { \mathrm { c } } 1 1 0 7 1 2 1 7 4 5 @ q q . c o m}$
}

Keywords: Hydraulic, Engine, Structure, Simulation method

Abstract. Hydraulic Confined Piston Engine (HCPE) is a new type power device especially suitable for hydrostatic driving vehicle. Its working process is influenced by complex coupling of liquid, solid and gas. Its working process simulation is the basis of later performance evaluation and design optimization. The structural principle of HCPE is described. The iteration method with stationary point is defined, and its whole operation process is discussed by way of output pressure computation as an example. Through simulation, the fluctuation of the angular speed of crankshaft coincides with the working process; the water pressure in cylinder has great instantaneous pulsation and phase step as outlet valve opening and inlet valve closing.

\section{Introduction}

For hydrostatic driving vehicle, the traditional power source, turning the thermal energy from fuel combustion into pressure energy, is engine-pump system, which hitherto is very mature, widely-used and longest-serving. On the other hand, engine-pump system has crucial problems also, such as the unreasonable matching between the engine and pump; the incompact and inefficient structure due to the long-way and too many intermediate links in energy conversion [1]. The Hydraulic Free Piston Engine (HFPE) has similar function as engine-pump system and higher efficiency. But HFPE is far from practical application for some technical bottlenecks [2-4]. So the structural principle of Hydraulic Confined Piston Engine (HCPE) was put forward, which integrates nearly all the merits of engine-pump system and HFPE. Its working process is influenced by the coupling effect of liquid, solid and gas; and the cooperation mechanism of various disciplines, such as system dynamics, material mechanics, fluid mechanics, thermodynamics, etc[5-7]. The traditional simulation on engine's property generally assumes the angular speed of crankshaft as const in one working cycle, which evidently is unreasonable, so iteration method with stationary point will be put forward in this paper.

\section{Structural principle}

The structural principle of HCPE is shown in fig.1; the combustion chamber likes the engine's corresponding part, and the pump chamber resembles a reciprocating plunger pump. The crankshaft chamber is used to constrain the reciprocating movement of piston via a crank-link mechanism, to results in the fixed stroke length, top dead center (TDC) and bottom dead center (BDC). The chamber also undertakes the works of timing, driving o coordination of auxiliary systems, inherited from traditional engine, including valve system, fuel supply system, lubrication system, cooling system, starter system, etc. The energy coming from fuel combustion is split into two portions at point A: one part is directly converted into hydraulic energy; the other is used to drive the crankshaft, the auxiliary system and rebound the piston-plunger module. Two or more plungers may symmetrically distribute around the axis of the power piston. As shown in Fig.1, the working process can be briefly described as follows: during the compression stroke, the piston is driven by a crank-link mechanism to compress the gases in the combustion chamber, at the same time; the pump chamber sucks low-pressure fluid in through the inlet valve. When the piston reaches TDC during compression stroke, the fuel is injected into the combustion chamber and burns. During the expansion stroke, the piston goes forward BDC, and high-pressure fluid flows out form pump chamber through the outlet valve due to the propulsion of plunger. 

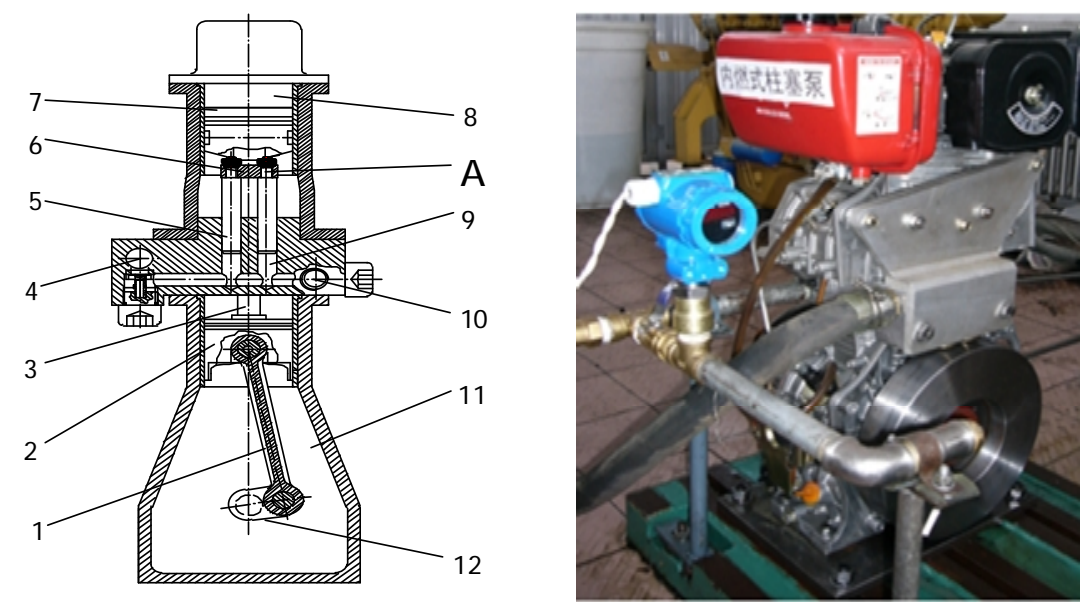

1. Connecting rod. 2. Guiding slide block. 3. Connecting bar. 4. Inlet valve; 5.Hydraulic plunger. 6. Connecting plate. 7. Piston. 8. Combustion chamber. 9. Pump chamber. 10. Outlet valve. 11.

Crankshaft chamber. 12. Crankshaft. A-Energy split-flow point

Fig. 1 Structural schematic and prototype of HCPE

\section{Iteration method with stationary point}

Iteration method with stationary point is an effective process simulation method for HCPE and nearly all other machines, whose operation will be described by taking the computation of HCPE's output pressure as an example.

Assuming a stationary point - a steady indicated condition with rotational speed $n_{0}$ and fuel throttle $\alpha$ is given, then the pressure $p_{\mathrm{a}}$ in combustion chamber can be figured out through thermodynamic simulation. For the stationary point, the average angular speed of crankshaft can be expressed as

$$
\omega_{0}=2 i \pi n_{0} /(60 i)
$$

Where $i$ is a coefficient, when the working cycle of HCPE has two strokes, $i=1$, and four strokes, $i=2$. Here the number of $i$ can not be omitted because the simulation cycle and convergence decision bases on one working cycle.

Now optionally providing an initial angular speed of crankshaft, $\omega^{(0)}$, and output pressure, $p^{(0)}$, after the first working-cyclic simulation, the angular speed turns into $\omega^{(1)}$. Before proceeding next working-cyclic simulation, the output pressure is adjusted to

$$
p^{(1)}=p^{(0)}+\Delta p^{(1)}
$$

Where $\Delta p^{(1)}$ is the increment of output pressure, expressed as

$$
\Delta p^{(1)}=c I_{0}\left\{\left[\omega^{(1)}\right]^{2}-\omega_{0}^{2}\right\} /\left(4 f_{\mathrm{p}} S\right)
$$

where $c$ is a coefficient of pressure adjustment $I_{0}$ is the rotational inertia of crankshaft-flywheel module. The equation is used to change output pressure according to the difference between simulating speed and indicated speed. Specifically, if simulating speed, $\omega^{(1)}$, is higher than indicating speed, $\omega_{0}$, the former output pressure, $p^{(0)}$, will be added $\Delta p^{(1)}$ as the initial value of next working-cyclic simulation, which will result in the output pressure energy of next cycle increase $c$ times as the kinetic energy increment of crankshaft-flywheel module in former cycle. As a matter of experience, the convergence rate is satisfactory when $c=2$.

For the $\mathrm{k}^{\text {th }}$ working cycle $(k=1,2,3 \ldots)$, the output pressure can be assumed as

$$
p^{(k)}=p^{(k-1)}+\Delta p^{(k)}
$$

Where $p^{(k-1)}$ is the out pressure of $\mathrm{k}-1^{\text {st }}$ working cycle; $\Delta p^{(k)}$ is the output pressure increment of the $k^{\text {th }}$ working cycle than the $\mathrm{k}-1^{\text {st }}$ :

$$
\Delta p^{(k)}=c I_{0}\left\{\left[\omega^{(k)}\right]^{2}-\omega_{0}^{2}\right\} /\left(4 f_{\mathrm{p}} S\right)
$$

Where $\omega^{(k)}$ is the mean angular speed of the $k^{\text {th }}$ working cycle.

Convergence criterion can be expressed as 


$$
\left|\omega^{(k)}-\omega_{0}\right| \leq \varepsilon
$$

Where $\varepsilon$ is the convergent precision, a tiny data, usually little than 0.01 for HCPE.

After convergence, the $p$ is just the output pressure $p_{\mathrm{c}}$, and all other state variables in the dynamic model are figure out also.

The flow chart of iteration method with stationary point is shown in fig.2.

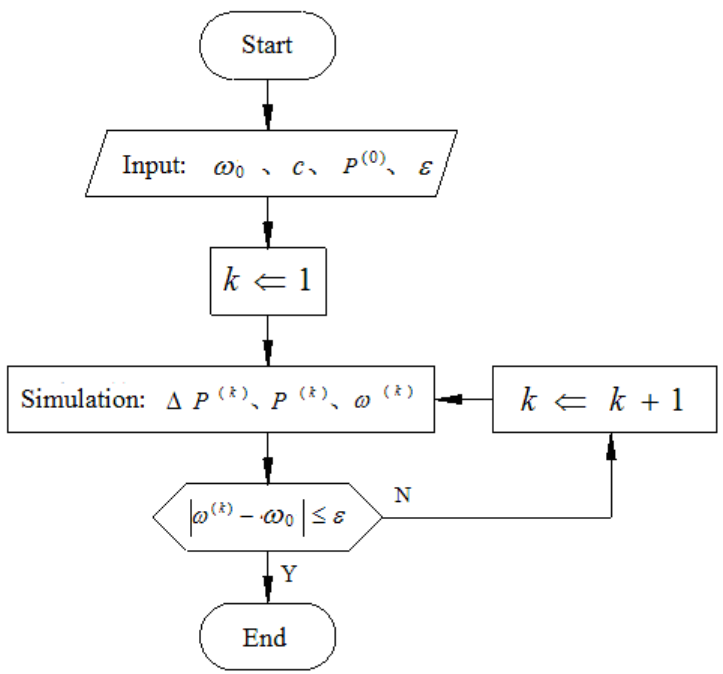

Fig.2 Workflow of iteration method with stationary point

So the principle of iteration method with stationary point can be expressed as: during the simulation of a system, taking an indicated working condition as the stationary point, if some necessary boundary conditions such as loads or displacements are given, after an cyclic simulating wherever from, a group of state variables reflecting the properties of the system can be figured out; before proceeding the simulation, only to reasonably adjust related state variables according to the difference between new state and the stationary point, then taking current condition as the initial condition to finish the next cyclic simulation, again and again, the working state will converged to the stationary point, and the final state variables will be the answer we are finding.

\section{Application examples of dynamic model and simulation method}

Angular speed simulation. When $n=2000 \mathrm{r} / \mathrm{min}$, fuel throttle is full, through simulation, the angular speed of crankshaft as a function of its rotational angle is shown in Fig.3. From the plot we can see, the flywheel speeds up in the expansion stroke during $0 \sim 180^{\circ}$, although simultaneously outputs high pressure fluid; afterwards slows down slightly in the compression stroke during $181 \sim 360^{\circ}$, because it cost small energy to suck fluid in and release exhaust gas out, the little fluctuation is resulted by the kinetic energy release of piston-plunger module nearly to TDC; afterwards decreases more evidently during $361 \sim 540^{\circ}$ for the suction stroke will cost more energy to suck gas in and output high pressure fluid; because the compression stroke vastly needs energy, although low pressure fluid is sucked in at this time, the speed decreases sharply during $541 \sim 720^{\circ}$. The angular speed ranges from $204.9876 \mathrm{rad} / \mathrm{s}$ to $212.3024 \mathrm{rad} / \mathrm{s}$ in one working cycle, and the running unevenness is about $3.49 \%$ 。 


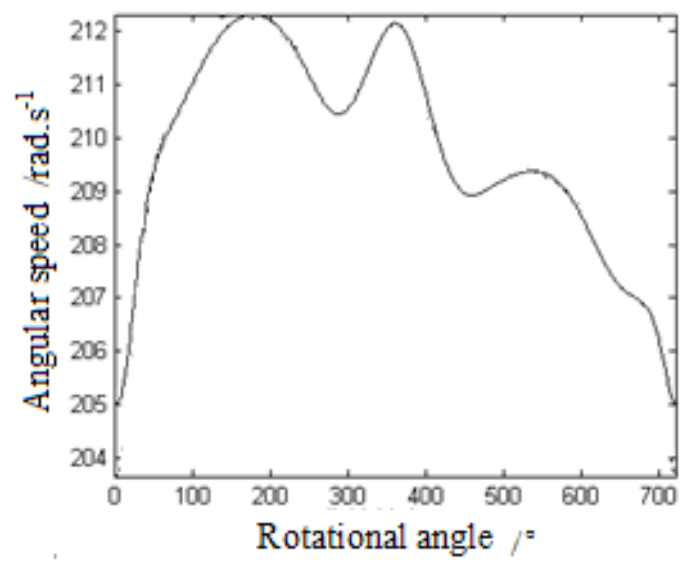

Fig.3 Angular speed as a function of rotational angle

Inner pump chamber pressure simulation. When working rotational speed $n=1500 \mathrm{r} / \mathrm{min}$, output pressure $p_{\mathrm{c}}=1.4 \mathrm{MPa}$ and inlet pressure $p_{\mathrm{s}}=0.1 \mathrm{MPa}$, the simulated pressure-time plot was shown in Fig.4. The simulation result shows that the water pressure in cylinder has great instantaneous pulsation and phase step when outlet valve opens and inlet valve closes, but is relatively steady in other periods. At the moment of inlet valve opening, the pressure in pump chamber is so lower even to zero, which means the plunger is isolated with the fluid and volumetric efficiency is influenced.

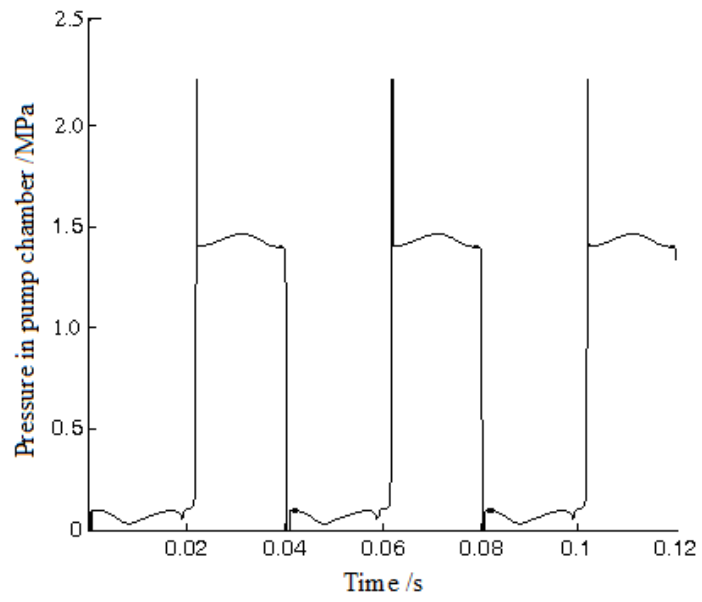

Fig.4 Pressure-time graph

\section{Summary}

HCPE is a new type power device especially used on hydrostatic driving vehicle, whose structural principle integrated the main character of HFPE and engine-pump system.

The iteration method with stationary point was put forward to realize more precise computation. The simulation result of angular speed of crankshaft, pressure in pump chamber, has shown the efficiency of the method.

\section{References}

[1] Y.S. Jiang, G.D. Zou, G. Xu, et al, Matching research of engine and hydraulic pump of full-hydraulic bulldozer, Construction Mechanization., 30(2009)49-52.

[2] R.Mikalsen, A.P.Roskilly, A review of free-piston engine history and applications, Applied thermal Engineering. 27(2007) 2339-2352.

[3] R. Michelson, E. Jones, A.P. Roskilly, Predictive piston motion control in a free-piston internal combustion engine, Applied Energy. 87(2010) 1722-1728. 
[4] X. Jin, Q.F. Li, H. Zhen, Motion characteristic of a free piston linear engine, Applied Energy. 87(2010) 1288-1294.

[5] H.X. Zhang, T.Z. Zhang, Q.H. Zhao, Load Analysis of Crankshaft of Axial Three-cylinder Hydraulic Confined Piston Engine, Applied Mechanics and Materials. 34-35(2010) 1692-1696.

[6] H.X. Zhang, T.Z. Zhang, W.C. Wang, Influence of Valve's Characteristic on Total Performance of Three Cylinders Internal Combustion Water Pump, Chinese Journal of Mechanical Engineering. 22(2009) 91-96.

[7] D.Z. Yang, H.X. Zhang , T.Z. Zhang, Structural principle and performance of three cylinder hydraulic confined piston engine, Applied Mechanics and Materials. 120 (2011) 316-320. 